\title{
Transit Oriented Development Around Upcoming Metro Stations in Pune and It's Effect on Livability
}

\author{
Vrinda Panse, Chetan Panse
}

\begin{abstract}
Due to rapid urbanisation over few decades, across the world, there is much stress on the infrastructure and transportation among the cities. For addressing issues of urban sprawl and congestion in the cities, transit oriented development (TOD) is emerging as an efficient mechanism. It principally aims for reducing car use and travel distances, by creating neighbourhoods with high density and pedestrian friendly and mixed-use design around transit stations. If effectively implemented, it can lead to sustainable development along the transit corridors. However, there are concerns, whether TOD will bring good quality of living for the residents near transit corridor. This study aims to understand the relationship between various parameters of TOD and its effect on livability in neighbourhoods near upcoming Metro corridors in Pune, India. The study tried to identify the various indicators of TOD. The effect of these indicators was analysed by applying a questionnaire survey of respondents along the metro corridor who would be the most affected due to the development. The analysis brought forth the factors affecting livability in the neighbourhood around the Metro corridor. This analysis will help to understand people's perception, which can serve as initial reference point for sustainable planning process for future development under TOD.
\end{abstract}

Keywords - Transit Oriented Development, livability, density, Metro corridor, Pune, India.

\section{INTRODUCTION}

Due to increasing population and growing economy, India is urbanising at a tremendous speed over past few decades. As per Census 2011, urbanisation has increased from $17.29 \%$ in 1951 to $31.6 \%$ in 2011 . Indian urban population is estimated to grow up to 600 million in 2030 as per McKinsey Global Institute report 2010. It has caused uncontrolled urban expansion due to migration from rural areas. As per Census 2011, 22\% of rural population migrated to urban areas from 2001-2011 and migration continues. Horizontal growth of cities has created urban sprawls. It has resulted in increased use of private vehicles.Cities are not planned considering transport systems for this unprecedented growth. Increased transportation and vehicle use has caused environmental degradation. The solution to urban sprawl lies in adopting a model for accommodating this influx of population and providing for better communication within cities.To reduce traffic congestion and improve environmental quality; cities are now applying Transit Oriented Development (TOD)

\footnotetext{
Revised Manuscript Received on September 10, 2019.

Vrinda Panse, Associate Professor, Marathwada Mitramandal College of Architecture, Pune, Maharastra, India.

(Email: vcpanse@gmail.com)

Dr. Chetan Panse, Associate Professor, SIBM Pune, Symbiosis International (Deemed University) (SIU), Pune, Maharastra, India.

(Email: chetanpanse@sibmpune.edu.in)
}

principles as one of the measures, in their urban development strategies.

Now that Indian Government has planned to develop 100 Smart Cities, Transit-Oriented Development (TOD) is seen as one of the key planning tools across the cities. It is a type of development around transit stations, having compact development in high-density population along transit corridor, imparting primary importance to pedestrian movement and easy access to transit stations.

Increasing urbanisation is adding pressure on urban infrastructure, which has given rise to numerous infrastructural projects across India. However, there are some bottlenecks in implementation works. Few of them being lack of funding, lack of synchronisation in State and local government or unawareness of people about the proposed development etc. (Richard R. Mudge, 1988) Local people, who are the stakeholders, many times do not have clarity about the project and they oppose it. People's misconceptions about the development may create various hurdles causing hindrance to local authorities in implementation. Realisation of the project and understanding its implications is important for better results. Therefore, it is necessary to understand the perception of people about the different policies of the government for successful implementation of the same.

Pune is the second largest city in Maharashtra and the eighth most populous city in India. It has a population of 31 lakh, with a population density of 12,777 persons per sq. $\mathrm{km}$ as per Census 2011. It has witnessed much industrial growth since 2000. Rapid urbanization has put the city's travel infrastructure at stress. To ease the situation, Pune Metro, a Metro rail based rapid transit system, is now under construction to serve the city of Pune. Pune Municipal Corporation (PMC) has proposed norms for 'Transit Oriented Development' for an area falling within $500 \mathrm{~m}$ from the metro stations. PMC has allowed increase in FSI up to four, as a tool for investment in metro.

According to Calthrope, (1993) Transit Oriented Development (TOD) is an efficient mechanism, to control urban sprawl and create sustainable cities where compact, mixed-use neighbourhoods are planned around public transit stops. TODs are significant in improving livability of urban life and building a desirable city image. High density, mixed land use, and pedestrian-friendly design are three main attributes of TOD built environment and are associated with numerous benefits for urban sustainability (Cervero, Murphy, FerrellL, Goguts, \& Tsai, 2004). As there is a

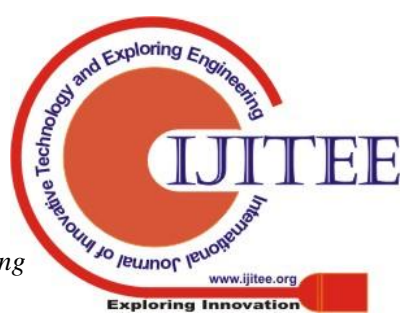


substantial change in land use, density and design for existing neighbourhoods, broadly inclusive community participation is necessary before executing TODs. Considering stakeholder's views is essential.

The local citizens or local people, which are the main users, form a significant stakeholder group who would be eventually benefitted by the project. It underlines the essential priority to take cognisance of this group in decision-making. Thus, participatory approach (strategic sampling) is to take stock of people's perceptions and opinions about the upcoming development. This paper aims to understand the perception of people about Transit Oriented Development and livability in the neighbourhood. The analysis from this research would help in narrowing down to certain set of priorities and aspirations addressed by the user group/stake holders.

The study has following objectives-

1. To study the norms of Transit Oriented Development

2. To study parameters of Transit Oriented Development and livability

3. To identify relationship between Transit Oriented Development and its application through perspective of livability

This study is done by taking survey of residents along Metro Corridor in Kothrud area of Pune city. The respondents comprise of the local residents from the study area. The sampling strategy is ratified random sample.

Economic aspects like land value, market rates etc. are not included in the study.

\section{LITERATURE REVIEW}

Transit Oriented Development has been defined in many ways based on New Urbanism concept (Robert, 1999). New urbanism theory, which mainly focuses on human scaled urban design, suggested solution to increasing suburban sprawls in cities around nineties. It encourages creating compact, mixed-use communities with access to public transport as an answer to urban sprawls. It gives new priorities for contemporary urban development. It reflects fundamental shift from old unsustainable car-oriented urbanism towards new urbanism. In this new urbanism, urban forms and land uses are closely integrated. It demands for efficient, low carbon impact and people centric travel modes like walking, cycling, and public transit system.

According to Calthrope, "A Transit-Oriented Development is a mixed-use community within an average 2,000-foot walking distance of a transit stop and core commercial area. TODs mix residential, retail, office, open space, and public uses in a walkable environment, making it convenient for residents and employees to travel by transit, bicycle, foot, or car" as cited in research paper (Rutul, Yogi, Kavina, \& Vishal, 2017).By reducing the need for driving and energy consumption, TOD is seen as a major solution for serious and growing problem of climate change and global energy security.
Basic principle of TOD is to provide high density, mixed use, pedestrian friendly development that is close to transit station maximising access to public transport and encouraging non-motorised options like walking and cycling, imparting improved quality of life to the residents. Social interactions are increased by walking on foot. Reduced parking spaces provide land for gardens, parks and open spaces and mix used spaces provide vibrant attractive city life. Cervero and Kockelman (Cervero \& Kockelman, 1997) have stated that three 'D's - Density, Diversity and Design, are the three main parameters of TOD. Further, two parameters were added as destination accessibility, and distance to transit. (Robert Cervero, 2009). TODs are planned in 400 to $800 \mathrm{~m}$ radius from a transit stop, which is considered an appropriate walking distance for the pedestrians. This will encourage walking and using public transport.

Density is the main attribute of TOD. Any public transit requires a threshold of ridership so that the transit becomes sustainable. To serve this function, high density of housing and other mix uses are planned near the transit stations. Further, concentrating urban density near transit stations is beneficial in limiting urban sprawls. In other way, it helps to retain agricultural lands of fringe areas, which would have been used for creating urban sprawls. It restricts land use and helps preserve the land that can be used for more open spaces and public parks. It reduces individual automobile travel in long run by promoting transit use. It also helps generate resources for investment in system improvement and expansion. By building of higher densities near transit station, the development can maximise the number of persons and services that can easily be reached by a short walking distance.

Diversity is also important parameter of TOD. It involves developing high quality urban living with a various types of buildings like residential, commercial, educational, institutional retails, offices, hotels etc. Availability of mix of uses in the surrounding creates synergy and diversity. Having mix uses in the community and providing easy access to transit promote the 24 hour activity. It increases ridership. This results in efficient use of public transport system as the travel happens in both the directions throughout the day.

Pedestrian friendly design is another important parameter of TOD. It focuses on providing building and spaces designed to human scale with added safety and comfort. It includes deigning of quality public realm with wide sidewalks, protection from traffic, providing street furniture and creating pedestrian friendly environment. It also aims for comfortable, enjoyable and easy pedestrian access to transit station. 


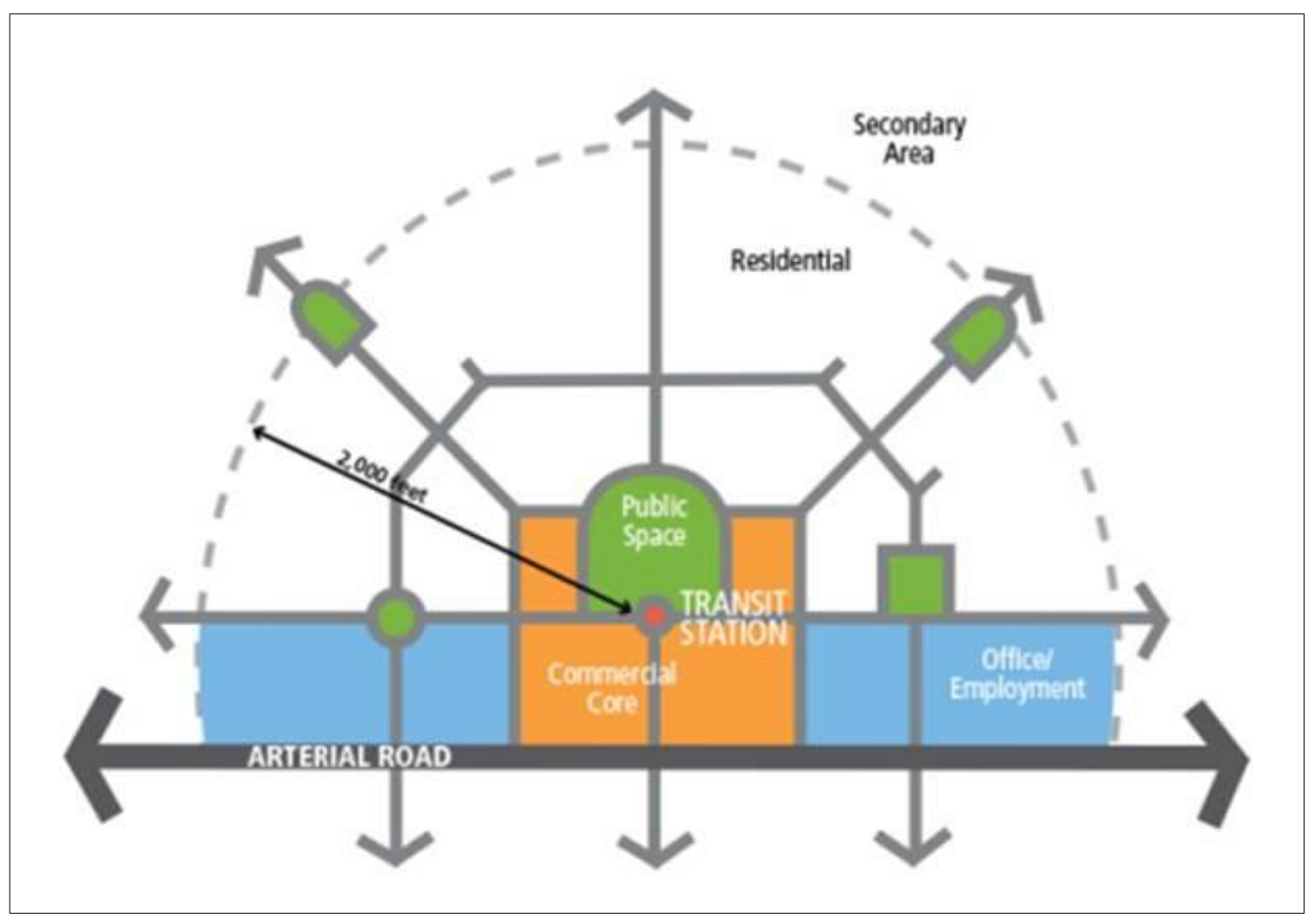

Figure 1 Diagram based on Peter Calthorpe's illustration of TOD. Source: As cited in a research paper-" Transit Oriented Development- Lessons from Indian Experiences" Working paper 36, Ahmedabad, Gujrat, India: Centre for Urban Equity , CEPT University.Fig 1 : Diagram based on Peter Calthorpe's illustration of TOD

As seen in Fig 1, transit oriented development is proposed in a walkable distance of 2000 feet from the transit station. It provides for commercial and other mix use development in core zone from transit station and residential area beyond that. It also shows green spaces for public use. TOD's mix residential, retail, office, open space, and public uses in a walkable environment make it convenient for residents and employees to travel by transit, bicycle, foot, or car.

TOD can be retrofit or refill development, redevelopment or Greenfield development. (Institute, 2018) Retrofit development includes developing those brownfield parcels of land, which have been used earlier and now, are reused for some different purpose. It involves increasing density with minimum intervention. When TOD is in already developed area, it is in the form of brown field development or redevelopment. Existing built environment is replaced in this type of development and a new layout is created by enhancing existing infrastructure and adding density. Green field development includes development of those areas, which are not previously used for urban development. TOD in this area focuses on distributing densities based on proximity to transit service. It includes maximising densities and FSI in primary and secondary station area zones.

There are various benefits of transit oriented development. It imparts higher quality of life with enhanced spaces to live, work and play. It provides for increased transit ridership and sustainable mode of transport. The public transit results in greater mobility with ease of moving around. It reduces traffic congestions and pollution in the cities. It results in less household expenditure due to reduced transportation and creates more affordable housing opportunities in the cities. As walking is promoted in pedestrian friendly design in
TOD, it encourages healthy lifestyle with more walking and reduced stress. Further due to mixed use type community establishments and walkable distances, there is increased footfall at the businesses. Due to less use of vehicles, it greatly reduces dependence on foreign oil and saves nation's money. It reduces sprawls and increases incentive for compact development. It is less expensive than building roads and sprawls. It encourages overall economic development of the area.

TOD in India -- The state of public transport in the majority of Indian cities has degraded over the years. With a primary objective of ensuring safe, affordable, sustainable access for growing no. of residents for jobs, education and other needs within the cities, Ministry of urban Development (MOUD) has formulated National Urban Transport Policy in 2006 and revised it in 2014 (National Urban transport Policy, 2014). It focuses on people mobility rather than vehicle mobility. MOUD has given much emphasis on TOD as a financing tool for such transit systems. Taking into consideration importance of TOD in national context, Government has announced "National Transit Oriented Development (TOD)" policy. (National Transit Oriented Development Policy, 2017) It promotes development near mass urban transit corridors, for addressing urbanisation challenges around India. The National smart City Mission launched by MOUD in 2015 (Smart cities-Mission Statement \& Guidelines, 2015), is leading the urban transformation in India with the aim for 
improving core infrastructure and giving good quality of life to the citizens. TOD is promoted as an urban growth strategy under this mission. Fifteen cities have proposed TOD in their Smart City Mission for sustainable development.

Pune is facing similar problems of urban sprawl as all other cities in the world. Increase in vehicles, traffic congestion, pollution and related issues are of high concern. For easing the situation and providing for better public transport, under Smart City mission, government has proposed Metro rail project in the city (DPR of Pune metro, 2015). Accordingly, total 3 metro lines have been proposed as: 1. PCMC-Swargate, 2.Vanaz-Ramwadi and 3.HinjewadiShivajinagar; comprising $54.85 \mathrm{~km}$ of total length. Construction has been started from June 2018. Pune Municipal Corporation has prescribed norms for Transit oriented Development (Pune DCR, 2017) for area of 500m around metro stations.

Livability has no uniform definition. Vuchic (Vuchic, 1999)defines urban livability as “...generally understood to encompass those elements of home, neighbourhood, and metropolitan area that contribute to safety, economic opportunities and welfare, health, convenience, mobility, and recreation". Urban design aspects or approach is based on livability concept (Southworth, 2016). This approach recognizes that design and structure of the neighbourhood planning is important in building communities in a sustainable way. It is a character of place, broadly inclusive of quality of life, sustainability, health and safety of community. It implements development based on quality of life. Quality of life and well-being are the concepts related to one's living condition or state.(Giap, Thye, \& Aw, 2014)Quality of life indicates people's satisfaction about residential environment, traffic, streets, safety, open spaces etc. Community is said to be livable when it is safe, has affordable and qualitative options for transport, housing and services and supports people of all ages (Jana Lynott).

The American Institute of Architects (2005) has stated ten principles for livable communities. The principles state that the design should be compact, pedestrian friendly human scaled design to encourage walking and reducing traffic congestions and improving health. It suggests for providing variety in housing, shopping, transport and recreation to create lively neighbourhood. It encourages mixed-use development to make vibrant and diverse communities. It suggests building vibrant public spaces and creating neighbourhood identity. It states importance of open spaces, green spaces for recreation and environmental conservation.

As the importance of livability is widely accepted, it is necessary to take cognisance of livability with TOD and it is to be considered in decision making by planners and authorities. Many researchers have taken surveys of people in already executed TOD areas to know about their opinions towards TOD attributes. TCRP Report 22(Transit Cooperative Research Programme, 1997) shows that survey respondents rated the most for TODs as an important factor in improving neighbourhood and livability and limiting the urban sprawls. It shows how public transit system contributes to the livability of neighbourhoods. Survey of Honolulu residents(Peter Flachsbart, 2010) shows that most of the residents supported idea for living near transit, within walking distance from essential shops and using bicycle or walking. High- density community living, green areas, and children play area facilities were preferred by the residents. Survey in Kuala Lumpur(Jamalunlaili Abdullah, 2016) also shows that respondents are satisfied with urban development with mixed use, high density and public spaces, but they are more concerned about pollution and less parking spaces. In one research paper, (Hayati Sari Hasibuan, 2014) the authors conclude that TOD contributes in urban environmental sustainability by reducing private vehicles, fuel consumption and consequent carbon emissions and maintains green open spaces for good quality of life.

These finding are relevant to the study in terms of people's insights about livability. There is a wide research done on gauging success of already executed TODs with respect to transit ridership and TOD success; however, it requires further research on whether upcoming new development due to the transit will bring desirable livability. The studies shall further focus whether residents' perception about their surrounding environment and quality of life will be addressed or not. This research deals with the study area around four metro stations in Kothrud area along Pune Metro. As per the byelaws specified by Pune Municipal Corporation, within $500 \mathrm{~m}$ from the metro stations, TODs are to be executed in near future. There is a need to know about people's perceptions about this development and its effect on livability.

\section{METHODOLOGY}

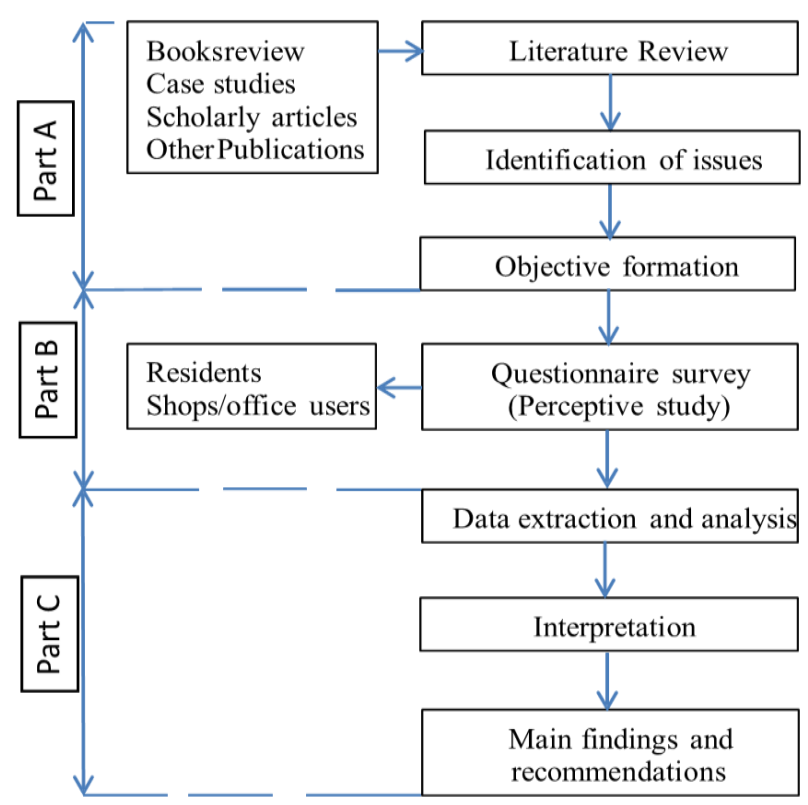

Figure 2 Methodology Chart

The study was conducted in three main stages -Part A, Part B and Part C.

Part A comprised of reviewing various books, case studies, scholarly articles and other relevant publications and identifying the issues. The objective was formed on its basis.

Part B, included forming a detailed questionnaire for survey of residents along Metro corridor

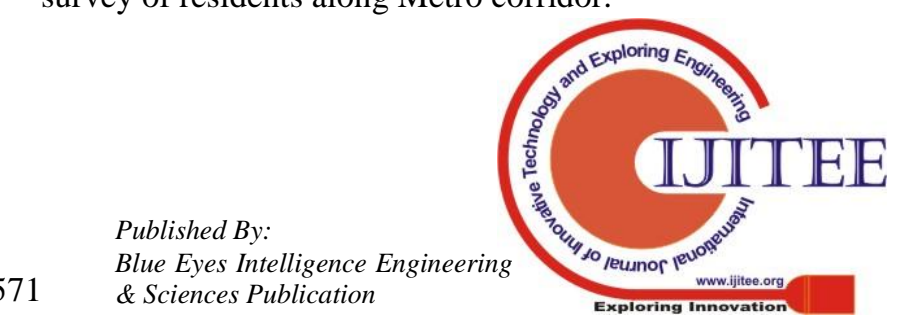


Basic social information of the participants like their name, gender, age, type of interviewee (flat or bungalow or shop user); and occupation (private or government employee, business, homemaker, student or other) was collected.

The questionnaire was divided in two parts, one for their opinion for awareness about metro project and second part consisted of resident's perceptions about livability in the neighbourhood.

First part of the questionnaire included three questions---

1. Whether residents are aware of upcoming new development in the area

2. Whether it has given good opportunity to their locality

3 . Whether it will increase or reduce pollution.

They were asked to rate their choice of preference, from one to five.

1-Strongly Disagree; 2 -Disagree; 3- Neutral; 4 Agree; 5- Strongly Agree

Second part of the questionnaire included twelve questions. It asked whether they would like to live in the area, if ---

1. It is located at a walking distance from metro shop,

2. It is near metro station,

3. It is located in a high-rise building,

4. It is a densely populated area,

5. It has fewer parking spaces,

6. Roads have wide footpaths and bicycle tracks,

7. Trees are planted along the roadside,

8. There are seating benches at roadside,

9. Streets are well lit,

10. It has common area for children to play,

11. It has gardens and landscaped area,

12. It is located in a quiet area without noise.

They were asked to rate their choice of preference, from one to five.

1-Strongly Disagree; 2 -Disagree; 3- Neutral; 4 Agree; 5- Strongly Agree

Using questionnaire, qualitative data was gathered through in-depth interviews and web survey. Five point Likert scale was used to gather the responses. One was 'strongly disagree' and five was 'strongly agree'.

In part $\mathrm{C}$ of the methodology, data was extracted and analysed. SPSS software was used to carry out exploratory factor analysis on the given data. Main findings and recommendations were made based on outcome of this analysis.

\section{DATA ANALYSIS \& RESULTS}

\section{Descriptive Analysis}

Survey was conducted through web questionnaire. Personal interviews of the residents in study area were also taken. Total 108 responses were recorded. Out of the total respondents, $56 \%$ were female and $44 \%$ were male respondents. $56 \%$ respondents were flat residents, $14 \%$ were bungalow residents, $16 \%$ were office workers and $14 \%$ were shop owners. $50 \%$ of respondents were from age group 31 to were from age group of 20 to 30 and $2 \%$ were under 20.65 $\%$ participants were from private or government service, $14 \%$ were businessperson, $13 \%$ were homemakers and $8 \%$ $50.22 \%$ were from age group 51 to 70 . $26 \%$ respondents

were students.

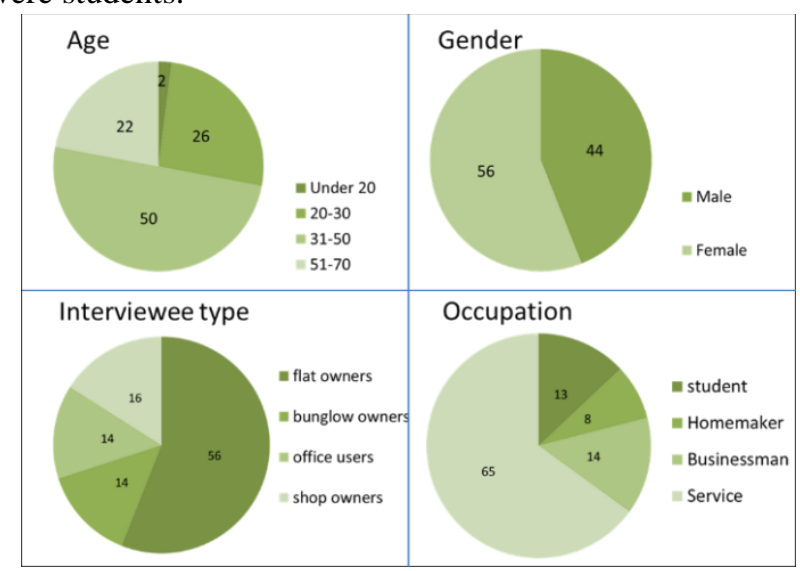

Figure 3 Demographic Analysis

Analysis of the survey revealed following aspects-

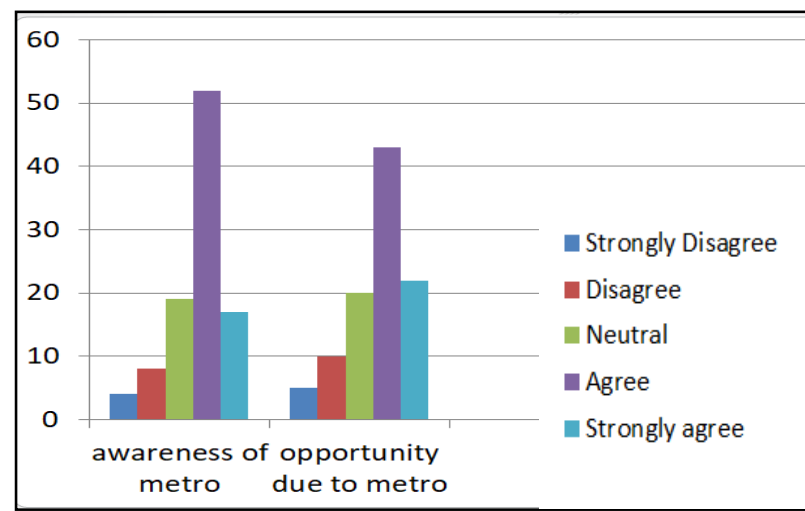

Figure 4

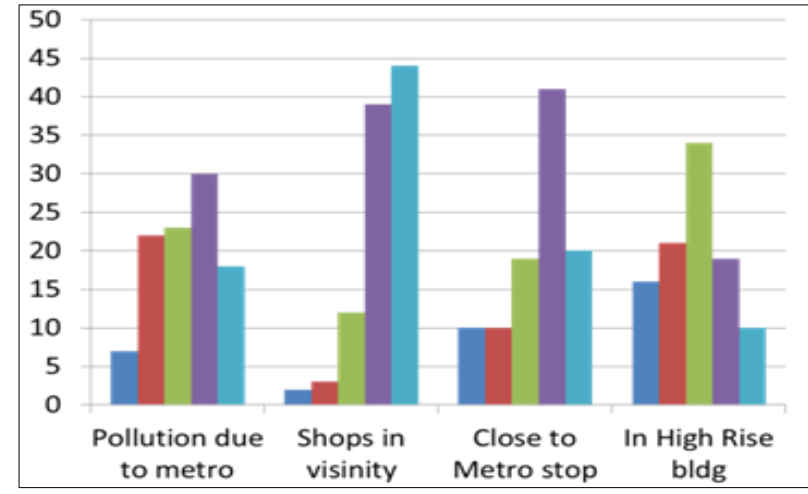

Figure 5

As graph in Fig 3 shows, overall 52\% respondents were aware of the upcoming new development due to Metro in their area.3\% respondents were totally unaware of the new development. $19 \%$ respondents are neutral about it. $42 \%$ people agreed that it has brought new opportunity in terms of physical development through new construction or redevelopment. $22 \%$ respondents highly agreed to it; while $5 \%$ respondents totally disagreed with it.

$41 \%$ respondents preferred having Metro stop in vicinity as an easy public transit option. $20 \%$ respondents highly agreed to it and $10 \%$ respondents totally did not prefer having metro in vicinity.

$38 \%$ people preferred to have their home near essential shops to fulfil daily needs at a walking distance and

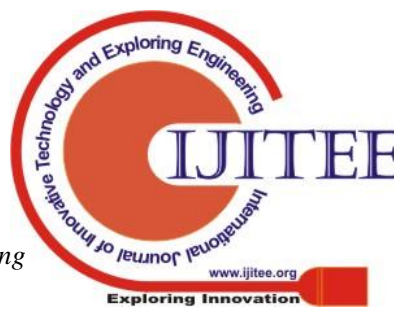


preferred mixed-use type of development. $43 \%$ respondents highly preferred it. Only $2 \%$ respondents did not prefer to have the shops in vicinity. $12 \%$ respondents were neutral about it.

Overall $28 \%$ people preferred to stay in high-rise buildings and $33 \%$ were neutral about it.10\% respondents totally disagreed to stay in high-rise building. $34 \%$ respondents were neutral about it.

$30 \%$ respondents were concerned about air and noise pollution due to metro while $22 \%$ were sure that there would not be any pollution due to metro. $7 \%$ respondents thought that metro would surely increase the pollution. $23 \%$ respondents were neutral about it.

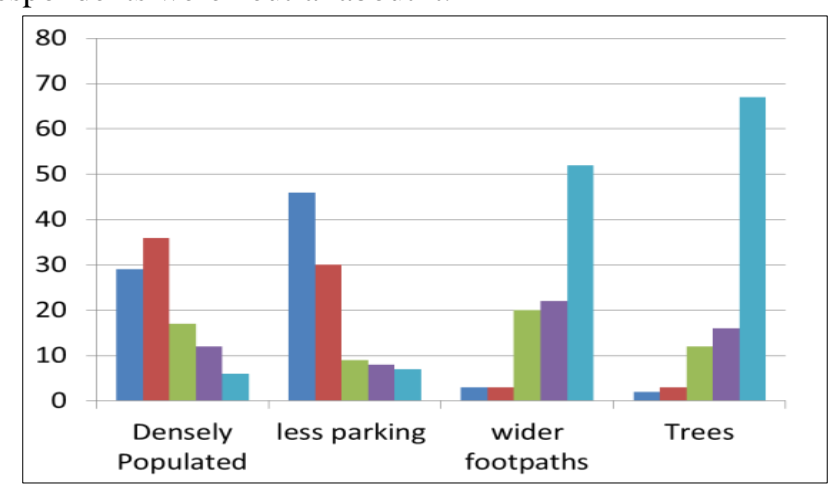

Figure 6

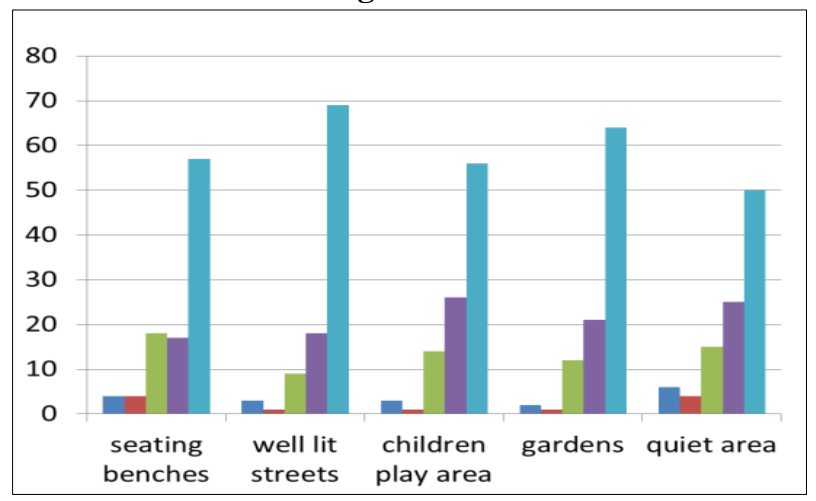

Figure 7

Density and fewer parking spaces are the main concerns of the respondents. Only $17 \%$ preferred to live in highdensity area and $16 \%$ were neutral about it. $29 \%$ respondents did not prefer at all to live in high-density area.

Inadequate parking was the main concerning issue for all the users. $45 \%$ people were highly concerned about fewer parking spaces in their building. They strongly disagreed to live with fewer parking spaces. Only 7\% respondents strongly agreed to stay where parking spaces are less. 9\% respondents were neutral about it.

Questions for preference for amenities like open spaces, wide footpaths, bicycle tracks, children play areas, trees and seating benches along roads, were answered with a very positive response. On an average, $50 \%$ respondents highly preferred to have these amenities while $25 \%$ moderately preferred it.

$52 \%$ respondents highly preferred to have wider footpaths. $20 \%$ respondents were neutral about it and only $2 \%$ totally disagreed with it.

$57 \%$ respondents highly preferred to have street furniture like seating benches along the roads. $18 \%$ respondents were neutral about it and only $4 \%$ respondents highly disagreed to have seating benches along the roads.
$69 \%$ people highly preferred to have streetlights. $9 \%$ respondents were neutral about it.

$56 \%$ respondents highly preferred to have children play areas in the neighbourhood. $12 \%$ respondents were neutral about it.

$67 \%$ people highly preferred to have tree plantation along roads and $63 \%$ respondents highly preferred to have gardens in their surroundings. Only $12 \%$ respondents were neutral about having tree plantations or gardens in the surrounding.

$50 \%$ residents highly preferred to stay in a quiet area without any noise. $6 \%$ respondents totally disagreed to stay in a quiet area. $14 \%$ respondents were neutral about it.

The analysis highlighted the fact that, if transit oriented developments are planned appropriately, people might like to stay in high-rise buildings and will be ready to welcome new lifestyle. People are not ready to stay in buildings where parking spaces are less. It indicates their present need of using private vehicles and need of parking spaces. They are also concerned about living in a higher density area. Also regarding noise and air pollution, $30 \%$ residents agreed that metro would cause air pollution, $18 \%$ highly agreed to it. $23 \%$ respondents were neutral about it. On an average, people are not sure whether metro will reduce the pollution. Outdoor spaces and amenities like gardens, green spaces, tree plantations and children play areas, roadside seating areas, wider footpaths and bicycle tracks etc. are of much importance to them. People highly prefer to have all these amenities in their surroundings. People also highly preferred to have well lit streets in their neighbourhood. It indicates that they are highly concerned about safety and security in the neighbourhood. Safety and security has the super most priority in their preferences.

\section{B. Exploratory Factor Analysis}

Exploratory Factor Analysis was carried out for the given data. The sample size was 108 . The extraction method was principal component analysis and Varimax rotation method with Kaiser Normalisation.

The Kaiser Meyer Olkin measure of sample adequacy index comes out to be 0.881 , which is much above 0.6 . This shows that the sample size of 108 is adequate for this analysis.

In addition, Bartlett's test of Sphericity is statistically significant $(\mathrm{p}=.000$ with $\mathrm{df} 78)$ which indicates that there exists a strong correlation among the components in the data. Total two-factors were extracted out of thirteen components given with the total variance explained is $59.59 \%$.

The rotated component Matrix shows that two factors with Eigenvalue more than one were extracted with the loading of individual components on factors more than 0.508. The smaller values of cross-loadings on each of the factors were suppressed to finally get these two factors with their loadings, as shown in the table in Fig 7 below. 


\begin{tabular}{|l|l|c|c|}
\hline & & 1 & 2 \\
\hline \multirow{5}{*}{ Positive aspects of TOD } & Road side trees & 0.888 & \\
\cline { 2 - 4 } & Chidren play areas & 0.886 & \\
\cline { 2 - 4 } & Well lit streets & 0.871 & \\
\cline { 2 - 4 } & Seating benches & 0.829 & \\
\cline { 2 - 4 } & Gardens & 0.814 & \\
\cline { 2 - 4 } & Quietness in the area & 0.806 & \\
\cline { 2 - 4 } & Footpaths and bicycle tracks & 0.783 & \\
\cline { 2 - 4 } Problems arising from & Shops in the vicinity & 0.622 & \\
\hline \multirow{5}{*}{ OOD affecting livability } & Densly populated & & 0.723 \\
\cline { 2 - 4 } & Less parking spaces & & 0.711 \\
\cline { 2 - 4 } & Air and Noise pollution & & 0.645 \\
\hline & Metro stop in vicinity & & 0.597 \\
\hline
\end{tabular}

Figure 8 -

Extraction Method: Principal Component Analysis

Rotation Method: Varimax with Kaiser Normalization The two factors that were extracted are-

1. Positive aspects of TOD

It includes-

Roadside trees, Children play area, Well-lit streets,

Seating benches, Gardens, Quietness in the area,

Footpaths and bicycle tracks and Shops in the vicinity.

2. Problems arising from TOD affecting livability

\section{CONCLUSION}

Livability ultimately depends upon how urban systems and processes perform in the cities. Urban design is implied for improving the quality of life around transit corridors to create a livable desirable place so that people will be attracted towards it. Transit oriented development brings about new development around transit stations with high density, mix use and pedestrian friendly design. Considering the perception of people, it shows that people are aware about the metro and subsequent new development, but they still feel that problems can arise. Policy effectiveness of future TOD is to be seen from perspective of comprehensive residential quality of life and people's perception. While implementing such policies, stakeholder's expectations should be considered. TOD, if implemented correctly, can lead to effective urban development along with minimising transportation issues in the cities.

\section{REFERENCES}

1. National Urban transport Policy. (2014, February). Retrieved January 7, 2019, from http://www.itdp.in/wpcontent/uploads/2014/11/NUTP-2014.pdf

2. DPR of Pune metro. (2015, November). Retrieved January 7, 2019, from Pune Municipal Corporation: pmc.gov.in/sites/default/files/DPR_of_Metro_NOV_201 5_2.pdf

3. Smart cities-Mission Statement \& Guidelines. (2015, June). Retrieved January 7, 2019, from http://smartcities.gov.in/upload/uploadfiles/files/SmartCit yGuidelines(1).pdf

4. National Transit Oriented Development Policy. (2017, May). Retrieved January 7, 2019, from http://www.indiaenvironmentportal.org.in/content/44228 7/national-transit-oriented-development-tod-policy/

5. Pune DCR. (2017, January 5). Retrieved January 7, 2019, from Pune Municipal Corporation:
https://pmc.gov.in/sites/default/files/DCR_PUNE_FINA L.pdf

6. Carlton, I. (2007). Histories of Transit-Oriented Development: Perspectives on the Development of TOD Concept. Institute of Urban and Regional Development.

7. Caves, F. w. (Ed.). (2012). Community Livability: Issues and Approaches to Sustaining the Well-Being of People and Communities. New york: Routledge.

8. Cervero, R., \& Kockelman, K. (1997, Septemeber). Travel demand and the 3Ds: Density, diversity, and design. Transportation Research Part D :Transport and Environment, 199-219.

9. Cervero, R., Murphy, S., Ferrell, C., Goguts, N., \& Tsai, Y.-H. (2004). TCRP Report 102. Washington D. C.: Transportation Research Board

10. Cervero, R., Murphy, S., Ferrell, C., Goguts, N., \& Tsai, Y.-H. (2004). TCRP Report 102. Washington D. C.: Transportation Research Board.

11. Giap, T. K., Thye, W. W., \& Aw, G. (2014). 'A new approach to measuring the liveability of cities: the Global Liveable Cities Index', World Review of Science, Technology and Sustainable Development (Vol. 11).

12. Hayati Sari Hasibuan, T. P. (2014). The Role of Transit Oriented Development in constructing Urban environmental Sustainability. 4th International Conference on Sustainable Future for Human Security, SustaiN 2013 (pp. 622-631). Kyoto: Elsevier.

13. India, J. (2017). Livability-Quotient. JLL India.

14. Institute, N. I. (2018). Transit Oriented Development for Indian smart Cities. Retrieved March 14, 2019, from tod.niua.org:

https://tod.niua.org/todfisc/book.php?book=1\&section=3

15. Jamalunlaili Abdullah, M. H. (2016). Characteristics and Quality of Life in TOD at Bandar Sri Permaisuri, Quala Lumpur. ASLI Conference on QoL.234, pp. 498-505. Indonesia: Elsevier.

16. Jana Lynott, R. H. (n.d.). The Livability Index 2018: Retrieved January 1, 2019, from https://livabilityindex.aarp.org/sites/default/files/AARP1 232_REPORT_Livability2018_Jun20v21.pdf

17. Jarvis, H. (2005). Work/Life City Limits: Comparative Household Perspectives. Palgrave Macmillan.

18. Kazuki, N., Femui, G., Vasinee, W., \& Hayashi, Y. (2016, March). Failure of Transit-Oriented Development in Bangkok from a Quality of Life Perspective. Asian transport Studies, 4(1), pp. 194-209.

19. Ltd., P. m. (2015). DPR Pune Metro. Pune: Pune Municipal Corporation.

20. Peter Flachsbart, M. C. (2010). Attitudes Toward Transit Oriented Development: Results of a Joint Telephone and Web-based Survey in Honolulu during Summer 2009. Urban Affairs Association 40th Conference. Honolulu, Hawaii: State of Hawai'i, Department of Transportation Highways Division and the U.S. Department of Transportation Federal Highway Administration.

21. Richard R. Mudge, K. I. (1988). Urban Infrastructure: Problems and Solutions. In K. I. Richard R. Mudge, Urban Change and Poverty (pp. 308-347). The national academic Press.

22. Robert Cervero, 1. O. (2009, June). Influences of Built Environments on Walking and Cycling: Lessons from Bogotá. International Journal of Sustainable Transportation, 3(4).

23. Robert, S. (1999, July). Transit-oriented development: moving from theory to practice. New Urban News by CNU, 4(4)

24. Rutul, J., Yogi, J., Kavina, P., \& Vishal, d. (2017, 
January). Transit Oriented Development-Lessons From Indian Experiences. Working paper 36. Ahmedabad, Gujrat, India: Centre for Urban equity, CEPT University.

25. Southworth, M. (2016). Learning to make liveable cities. Journal of Urban design, 21(5), 570-573.

26. Transit Cooperative Research Programme. (1997). TheRole of Transit in Creating Livable Metropolitan Communities. New York: National academy Press.

27. Vuchic, V. R. (1999). Rutgers Center for Urban policy Rserarch.

\section{AUTHORS PROFILE}

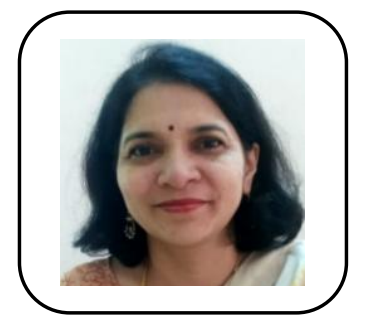

Vrinda Panse is Associate Professor at Marathwada Mitramandal College of Architecture, Pune. She has done her Master's in Environmental Architecture from BNCA, Pune and B. Arch. from BKPS, Pune. She has a professional experience of twenty nine years and has designed various architectural projects.

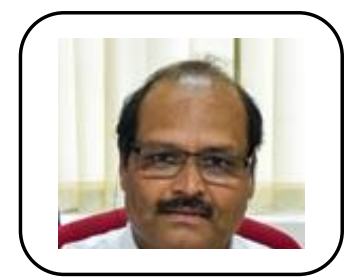

Dr. Chetan Panse is Associate Professor, SIBM Pune, Symbiosis International (Deemed University) (SIU). $\mathrm{He}$ is a Production Engineering graduate. $\mathrm{He}$ has done $\mathrm{PhD}$ in Management and also completed PGDIE from National Institute of Industrial Engineering (NITIE), Mumbai. Given the interdisciplinary background, his research area includes, Project Management \& Operations \& Supply Chain Management. He has published many research articles in International as well as National Journals. 